This item was submitted to Loughborough's Research Repository by the author.

Items in Figshare are protected by copyright, with all rights reserved, unless otherwise indicated.

\title{
Occupational safety and health and smaller organisations: research challenges and opportunities
}

PLEASE CITE THE PUBLISHED VERSION

http://dx.doi.org/10.1080/14773996.2016.1239357

\section{PUBLISHER}

(c) Taylor \& Francis

\section{VERSION}

AM (Accepted Manuscript)

\section{PUBLISHER STATEMENT}

This work is made available according to the conditions of the Creative Commons Attribution-NonCommercialNoDerivatives 4.0 International (CC BY-NC-ND 4.0) licence. Full details of this licence are available at: https://creativecommons.org/licenses/by-nc-nd/4.0/

\section{LICENCE}

CC BY-NC-ND 4.0

\section{REPOSITORY RECORD}

Pinder, James, Alistair Gibb, Andrew Dainty, Wendy Jones, Michael Fray, Ruth Hartley, Alistair Cheyne, et al.. 2016. "Occupational Safety and Health and Smaller Organisations: Research Challenges and Opportunities". Loughborough University. https://hdl.handle.net/2134/22779. 
OCCUPATIONAL SAFETY AND HEALTH AND SMALLER

ORGANISATIONS: RESEARCH CHALLENGES AND OPPORTUNITIES

James Pinder ${ }^{1}$, Alistair Gibb ${ }^{1}$, Andrew Dainty ${ }^{1}$, Wendy Jones ${ }^{1}$, Mike Fray ${ }^{2}$, Ruth Hartley $^{3}$, Alistair Cheyne ${ }^{3}$, Aoife Finneran ${ }^{4}$, Jane Glover ${ }^{5}$, Roger Haslam ${ }^{2}$, Jennie Morgan $^{6}$, Patrick Waterson ${ }^{2}$, Elaine Yolande Gosling ${ }^{7}$, Phil Bust ${ }^{1}$ and Sarah Pink ${ }^{8}$

${ }^{1}$ School of Civil \& Building Engineering, Loughborough University

${ }^{2}$ Design School, Loughborough University

${ }^{3}$ School of Business \& Economics, Loughborough University

${ }^{4} \mathrm{RSSB}$

${ }^{5}$ Department of Business and Labour Economics, University of Birmingham

${ }^{6}$ Department of Sociology, The University of York

${ }^{7}$ PA Consulting Group

${ }^{8}$ RMIT University

\begin{abstract}
Despite the prevalence of small and medium-sized enterprises (SMEs) and micro organisations, comparatively little is known about how such organisations approach occupational safety and health (OSH). Research has tended to present a negative picture of OSH practices in smaller organisations. This paper discusses some of the challenges to researching OSH in SMEs and micro organisations and how these challenges can be overcome. It draws lessons and experiences from a qualitative study involving 149 structured interviews, nine short-term ethnographies and 21 semistructured interviews with owners and employees in SMEs and micro organisations
\end{abstract}


from a broad cross-section of industry sectors in the UK, including construction, retail, healthcare, logistics and agriculture. Data from the study suggest that the established boundaries between micro, small and medium-sized enterprises are less meaningful in an OSH context - OSH practices are influenced more by the culture of the organisation, the type of work being undertaken and the sector that an organisation operates in. OSH practices in SMEs and micro organisations tend to reflect the more informal characteristics of such organisations, with more emphasis (than many larger organisations) on tacit knowledge, learning by doing and improvisation. Such practices should not necessarily be assumed to be unsafe or incompatible with formalised OSH.

Key words: Enactments; learning; micro organisations; SMEs; tacit knowledge. 


\section{Introduction}

Small and medium-sized enterprises (SMEs), micro organisations and sole traders ${ }^{1}$ comprise the majority of businesses across all sectors in many countries, however comparatively little is known about how such organisations approach occupational safety and health (OSH). Although there is an increasing amount of literature on the subject, the body of empirical evidence on OSH in smaller organisations is still relatively limited and spread thinly across a wide range of industry sectors and geographical locations. This lack of evidence is usually attributed to the difficulties of accessing and studying SMEs and micro organisations, an argument that is certainly valid and explored further in this paper. However, we also suggest that the lack of evidence on OSH in SMEs and micro organisations is a symptom of what Dekker (2014) called the 'bureaucratization of safety', with its emphasis on hierarchy and formalised rules - characteristics that are more commonly associated with larger organisations.

In this paper we suggest that the bureaucratization of OSH has not only led to SMEs and micro organisations being given less attention in the OSH literature, but has also meant that when empirical studies have been undertaken in smaller organisations they have tended to present an overly negative picture of OSH practices because they are being viewed through what Dekker (2003) described as a 'model 1' viewpoint. A 'model 1' view of OSH, according to Hale and Borys (2013, p.207), is one“... in which rules are seen as static, comprehensive limits of freedom of choice, imposed on operators at the sharp end and violations are seen as negative behaviour to be suppressed." In this paper we describe how some SMEs and micro organisations

\footnotetext{
${ }^{1}$ For the purpose of this paper, micro, small and medium sized enterprises are organisations employing less than 10, 50 and 250 people, respectively. Sole traders (or proprietors) are businesses in which there is one self-employed person - the owner.
} 
develop OSH practices that, in some cases, might not be in line with formal recognised practice, but nevertheless appear to be safe within the context that they are being applied. Such practices are more reflective of a 'model 2' approach to OSH that views: operatives as being central to rule making; social processes as key to rule use; and rule-making as a continuous, dynamic process (Hale and Borys, 2013; p.218).

The aim of this paper is to examine the challenges of researching OSH in smaller organisations, both from a practical point of view (how we access and categorise smaller organisations) and a theoretical point of view (how we make sense of OSH practices in smaller organisations). This paper is based on the findings and experiences of a two-year study (Gibb et al., 2016a) of OSH in smaller organisations in the United Kingdom (UK), funded by the Institution of Occupational Safety and Health (IOSH), in which we engaged with owners and employees in SMEs and micro organisations from a range of industry sectors, including, amongst others, logistics, healthcare and construction (Table 1). Our research involved 149 structured interviews, nine short-term ethnographies and 21 semi-structured interviews, the data from which provided insights into sources of OSH knowledge in smaller organisations and the ways in which this knowledge is enacted, or put into practice. In the next part of this paper we explain in further detail Dekker's (2003) contrasting models of OSH practice, so as to provide a theoretical basis for findings discussed later in this paper. We then discuss some of the practical challenges involved in accessing OSH practices in smaller organisations and provide examples of how these challenges can be overcome. In section 4 of this paper we explore the ways in which smaller organisations are usually categorised and the nuances in organisational types and relationships that can have implications for our understanding of OSH practices in smaller organisations. This is followed by a discussion of how the traditional top- 
down, rational (model 1) approach to OSH has influenced our understanding of OSH practices in SMEs and micro organisations. We conclude this paper by considering the opportunities for extending and deepening our understanding of OSH practices in smaller organisations.

Table 1: Number of participants engaged with, by organisation size and sector

\begin{tabular}{|c|c|c|c|c|c|}
\hline \multirow[b]{2}{*}{ Sector } & \multicolumn{4}{|c|}{ Size of organisation } & \multirow[b]{2}{*}{ Total } \\
\hline & Sole trader & Micro & Small & Medium & \\
\hline Agriculture & 6 & 16 & 0 & 0 & 22 \\
\hline Automotive & 0 & 1 & 1 & 0 & 2 \\
\hline Beauty therapy & 1 & 0 & 0 & 0 & 1 \\
\hline Construction & 14 & 11 & 7 & 8 & 40 \\
\hline Consultancy & 0 & 0 & 2 & 0 & 2 \\
\hline Engineering & 0 & 3 & 0 & 0 & 3 \\
\hline Healthcare & 4 & 5 & 4 & 7 & 20 \\
\hline Hospitality & 1 & 8 & 2 & 0 & 11 \\
\hline Information technology & 0 & 0 & 0 & 1 & 1 \\
\hline Leisure & 1 & 0 & 0 & 0 & 1 \\
\hline Logistics & 6 & 14 & 2 & 12 & 34 \\
\hline Maintenance & 1 & 1 & 0 & 1 & 3 \\
\hline Manufacturing & 0 & 6 & 0 & 0 & 6 \\
\hline Mining & 1 & 0 & 0 & 5 & 6 \\
\hline Performing arts & 2 & 2 & 0 & 0 & 4 \\
\hline Retail & 4 & 14 & 0 & 0 & 18 \\
\hline Tourism & 0 & 2 & 3 & 0 & 5 \\
\hline Total & 41 & 83 & 21 & 34 & 179 \\
\hline
\end{tabular}

\section{Background theory}

Over the last decade or more, an ongoing debate in safety research has focused on the extent to which OSH is a product of rule-based compliance, or instead a practiced or more contingent cognitive activity. The underlying emphasis of this debate has been on the extent to which those who are subject to OSH policy use rules to define their 
role or prefer more independent or contextual ways of working. The ongoing nature of this debate is unsurprising given the focus of OSH professional practice on risk management and regulatory compliance, and the psychological foundations of much research in the $\mathrm{OSH}$ field. However, a result of risk management being so enshrined in safety practice, and the behavioural emphasis of so much safety scholarship, is that the safety research community is left having to simultaneously confirm and deny the importance of worker independent thought (Dekker, 2012). Moreover, efforts to understand $\mathrm{OSH}$ knowledge tend to focus on either top-down rationalistic perspectives, or bottom-up constructivist models of knowledge. Such debates have therefore largely proceeded along parallel trajectories with relatively little work examining formal and tacit OSH knowledge in practice. Tacit knowledge is knowledge that is not codified or explicated. According to Leonard and Sensiper (1998, p.213) "The common element in such knowing is the inability of the knower to totally articulate all that he or she knows”.

In line with the notion of factional approaches to OSH, Dekker (2003) outlined two perspectives on rule development in the workplace: model 1 - procedure application through rule following; and model 2 - procedure application as substantive cognitive activity. Hale and Borys (2013) developed these models further, outlining the advantages and disadvantages of each. From a model 1 perspective, there is 'one best way', which can be dictated by formal procedures or rules. These are devised in advance by 'experts' and imposed and implemented by management. Hale and Borys (2013, p.212) suggest that "The rules are chosen as having as few as possible valid exceptions and cover topics such as smoking, seat belts, gas tests, work permits, fall protection at height, speed limits and journey management plans”. This is a logical and rational approach; both the rules and the consequences of breaking them are 
explicit. From an organisational perspective, this is classic Taylorism but it has also been discussed more recently in the context of public sector organisations (Diefenbach, 2009). Rules of this type are said to be good for novices and useful when 'golden rules' (key rules or checklists which aid fast working or must not be broken because of the extreme consequences) are necessary. However, this approach cannot deal with anomalies well, can result in a blame culture and disempowers workers.

A model 2 approach to OSH indicates that a range of behaviours are acceptable within permissible boundaries. Rulemaking is ongoing and dynamic, evolving in an ever changing working environment. This approach is said to deal better with the ambiguous realities of work. Hale and Borys (2013, p.211) describe how "The real experts in this conceptualisation are the operators (pilots, surgeons, maintenance fitters, seamen), whose ability to conduct and navigate this dynamic process of negotiation and construction of rules is seen as an essential part of their skill and identity." However, there are limitations to this approach because it lacks transparency and can therefore be difficult to audit and problematic for novices. The role of the organisation is diminished and the active management of rules is undervalued.

Dekker (2003) indicates that where there is a focus on model 1, it results in a 'double bind'. A 'double bind' occurs when there is a gap between procedures and practice, that is to say workers can fail to adapt to a problem when adaptation is necessary or workers attempt an adaptation which results in a problem. Rather than seeking to increase compliance, through the application of pressure, organisations should try and understand the gap between procedures and practice, and address competencies which will help workers adapt to new situations. Moreover, Hale and Borys (2013) suggest 
that a combination of the classical rational and constructivist approaches will enable organisations to manage safety more effectively. They propose a "Framework of rule management", and call for more research exploring how rules are used in practice and ethnographic research in this field. We suggested that undertaking such research with SMEs and micro organisations is particularly valuable, given the relative paucity of research into $\mathrm{OSH}$ in smaller organisations.

\section{Accessing smaller organisations}

SMEs and micro organisations play a key role in the UK economy and provide widespread employment either through self-employment or further job creation. According to the Federation of Small Businesses (2016), in the UK at the start of

2015 SMEs and micro organisations accounted for:

- $99.3 \%$ of all private sector businesses;

- $60 \%$ of all private sector employment; and

- $47 \%$ of all private sector turnover.

However, despite their prevalence, smaller organisations have traditionally been seen as "hard to reach" by government bodies and by researchers in a range of disciplines. Curran and Blackburn (2000, p.59) suggested that “... one of the most difficult problems in small business research is accessing smaller businesses.” Possible explanations are that they:

- tend to be 'less visible' than larger organisations, with fewer external points of contact;

- may be apprehensive about sharing their views and experiences with outsiders;

- can be sceptical about the value or relevance of participating in research 
projects, which might be perceived as a 'waste of time'; and

- $\quad$ are often too busy to engage in research projects, because time spent not working usually means lost income.

These difficulties can be exacerbated when researching a sensitive topic such as OSH - which people in larger organisations can also be reticent to talk about - because potential participants may feel that their knowledge or working practices are being scrutinised.

Table 2 summarises the barriers that we encountered during our research with smaller organisations and the ways in which we sought to overcome them. As with other 'hard to reach' groups, the difficulty of identifying a suitable sample frame has frequently been cited as a barrier to accessing smaller organisations (Curran and Blackburn, 2000; Lewis et al., 2007). This is a particular problem in studies that are seeking to collect representative samples of data and generalise findings to a broader population, however this was deemed to be less of an issue in our study because we adopted an inductive and interpretative approach that focused on depth rather than breadth of insights. Our emphasis was therefore on understanding the meaning rather than frequency of OSH practices. We engaged with participants in a wide range of sectors, including construction, healthcare, retail, tourism, mining, agriculture and hospitality. Broadening our sample in this way enabled us to gain insights into a more diverse range of work settings, with different levels of risk, and explore with more confidence the interplay between type of work being undertaken and OSH knowledge and practices. 
Table 2: Barriers to accessing smaller enterprises and approaches to overcoming them

\begin{tabular}{|l|l|}
\hline Barriers to accessing participants & Approach adopted in our research \\
\hline $\begin{array}{l}\text { Less visible and fewer external points } \\
\text { of contact (lack of suitable sample } \\
\text { frame). }\end{array}$ & $\begin{array}{l}\text { Purposive and snowball sampling using } \\
\text { existing contacts. }\end{array}$ \\
\hline $\begin{array}{l}\text { Too busy to participate (potential for } \\
\text { lost income). }\end{array}$ & $\begin{array}{l}\text { Interviewed participants in their place of } \\
\text { work. Employed a combination of } \\
\text { structured and semi-structured } \\
\text { interviews and short-term } \\
\text { ethnographies. }\end{array}$ \\
\hline $\begin{array}{l}\text { Sensitive subject (fear of being } \\
\text { scrutinised). }\end{array}$ & $\begin{array}{l}\text { Began interviews by not talking about } \\
\text { OSH. Carefully worded interview } \\
\text { questions and (when required) provided } \\
\text { participants with copy of the questions } \\
\text { in advance. }\end{array}$ \\
\hline $\begin{array}{l}\text { Apprehensive of sharing information } \\
\text { with outsiders. }\end{array}$ & $\begin{array}{l}\text { Explained that an experienced team of } \\
\text { academic researchers, from a respected } \\
\text { university, were undertaking the study. } \\
\text { Provided assurances that any } \\
\text { information provided would be } \\
\text { anonymised and data would not be } \\
\text { shared with third parties. }\end{array}$ \\
\hline $\begin{array}{l}\text { Sceptical about the value of academic } \\
\text { research. }\end{array}$ & $\begin{array}{l}\text { Provide clear information about the } \\
\text { purpose of the study and how the } \\
\text { research will inform policy and practice. }\end{array}$ \\
\hline Difficulties in accessing employees. & $\begin{array}{l}\text { Built trust and a rapport with owners } \\
\text { and managers. }\end{array}$ \\
\hline
\end{tabular}

We identified participants through a combination of purposive and snowball sampling. The former involved choosing respondents who we felt would provide useful insights into the topic; the latter involved respondents referring us to other possible respondents, such as colleagues. Participants were selected purposively for maximum variation so that our research covered a range of different work settings. For instance, members of the research team visited a local market one morning and interviewed the stallholders who worked there. On another occasion a member of the research team interviewed an electrician who was working in their home. Engaging 
with participants in their own workplace provided us with a very diverse range of participants who might have otherwise been difficult to access. This approach also meant that we were able to reduce the amount of time required for people to participate in our research, and enabled us to engage with them in their work environment and discuss their OSH practices 'in-situ' 2 . In other cases, the research team used their existing contacts to arrange interviews, which sometimes resulted in additional interviews with other participants. For example, we interviewed the owner of a micro physiotherapy practice (who was known to a member of our team), who then arranged for us to interview six other people from the practice, including three sole trader physiotherapists. The benefits of snowball sampling have been discussed elsewhere (Atkinson and Flint, 2001) in relation to hard to reach groups and proved to be an effective approach in our study.

Owners, managers and employees in smaller organisations tend to be 'time poor' because of the financial and other resource constraints that they have to contend with. As well as interviewing participants in their place of work, we overcame this barrier by using a combination of structured interviews, semi-structured interviews and shortterm ethnographies (as summarised in Figure 1). Structured interviews, involving the use of a standardised list of questions and follow-up questions, were used in situations where we had limited time to engage with participants and/or when we approached participants on an impromptu basis. The structured interviews typically lasted for around 10-15 minutes and approximately one third of them were recorded and transcribed; the remainder were undertaken in situations where it was not possible to record the conversations, so detailed field notes were taken instead. Where possible, multiple interviews were held within the same organisation in order to access multiple

\footnotetext{
${ }^{2}$ This provided additional insights, for instance in situations where a participant demonstrated a particular practice.
} 
(e.g. owners' and employees') perspectives on the same issues. The semi-structured interviews comprised a more flexible set of questions and were undertaken after the initial coding of the data from the structured interviews and emerging findings had been generated from the ethnography. This enabled us to introduce new areas of inquiry into the semi-structured interviews and explore previously identified themes in greater depth. For instance, participants in the structured interviews made reference to the importance of the knowledge they had acquired when working in other organisations - and the ways in which they had adapted and applied that knowledge in their current roles - so this was an issue that we made a point of exploring in more depth in the semi-structured interviews. These interviews were arranged in advance, typically lasting between 45 minutes and one hour, and were recorded with the interviewee's prior written consent and then transcribed.

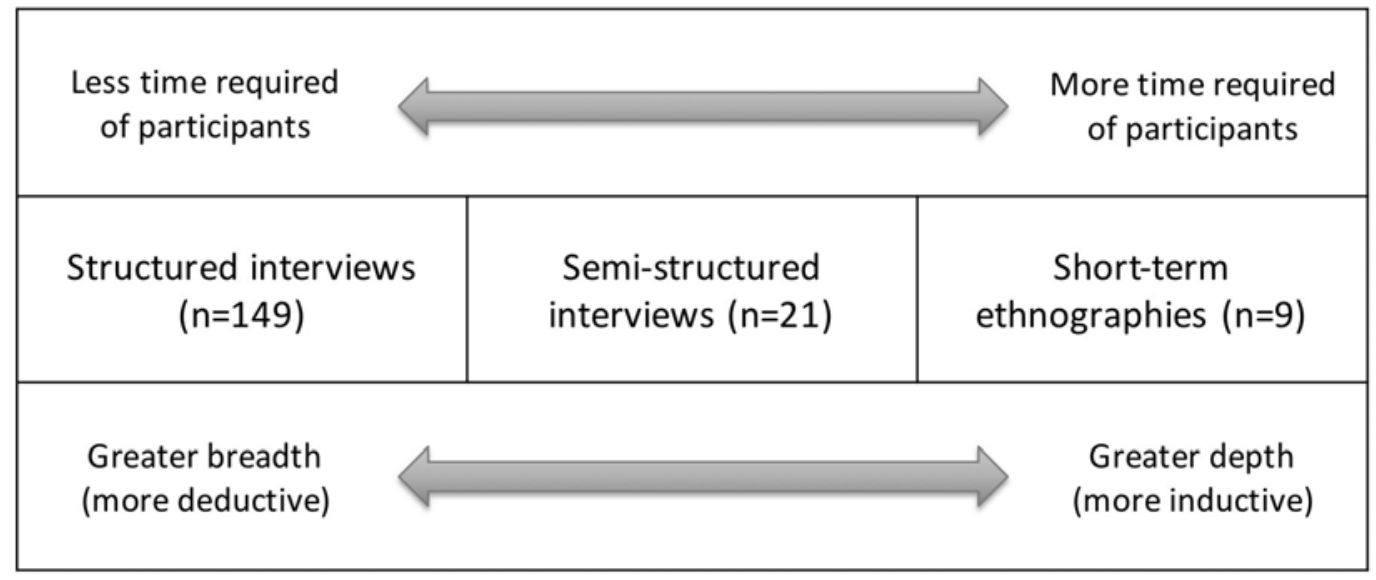

Figure 1: Summary of the data collection methods employed in our research

It was not feasible or appropriate, given the practical realities of engaging smaller firms, to use full ethnographic methods requiring several weeks of intensive fieldwork. We therefore used short-term ethnographic methods in a more time-limited way: spending hours rather than weeks with participating companies and individuals. 
These methods were collaborative and participatory, with participants being made aware from the outset of the kinds of engagements the researcher wished to fashion. The short-term ethnographies focused on the 'intense encounter' (Pink and Morgan, 2013) and enabled us to explore understandings, perceptions, and actual practices that are not so easily explored using non-ethnographic methods, for instance, because they are unspoken or taken for granted elements of everyday working life. Research activities were collaborative and participatory, providing reflexive opportunities for participants to 'tell' as well as 'show' us how they 'knew how' to work in safe and healthy ways. This was achieved through in-depth interviews with participants, 'guided tours' of their workplaces, observing them undertaking workplace activities in-situ and, where appropriate, the use of photography. Taking part in the research provided participants with an opportunity to: consider the work that they do in new ways; articulate practices that often go unnoticed (being routine and habitual); and make visible the many different ways that they work in a safe and healthy manner. Many previous empirical studies on $\mathrm{OSH}$ in smaller organisations have tended to examine the issue from the perspective of the business owners. This perhaps reflects the fact that owners are the first point of contact in many smaller organisations (thereby assuming the role of gatekeeper) and are also seen to be the key influencers and decision-makers in relation to $\mathrm{OSH}$, something which (as we discuss later in this paper) is indicative of a 'model 1' approach to researching OSH. However, by focusing on business owners, previous studies have (intentionally or unintentionally) privileged the views of owners and marginalised those of employees. Our research therefore sought to adopt a more balanced approach by foregrounding the views of employees as well as those of owner-managers. In total we engaged with 178 individuals in 110 companies. Of those 178 individuals: 70 were employees; 55 were 
owner-managers; 45 were owners; and eight were managers. For practical reasons, we tended to approach business owners in the first instance, in order to build a rapport with them and provide a basis for negotiating further access to employees. In most cases, the process of building trust with owners was reinforced by actually interviewing them, so that they could see what participation in the study involved and be reassured that the research would not harm their employees or their business.

A key challenge in researching OSH in smaller organisations is overcoming participants' reticence to engage with academic researchers, either because participants do not see the value in (academic) research and/or because they are wary of sharing (potentially sensitive) information with strangers. We overcame these problems: through our pragmatic approach to sampling participants (e.g. by using existing contacts and through snowball sampling); by providing participants with clear information about the purpose of the research and its role in influencing OSH policy and practice; and by reassuring participants about how the data being collected would (and would not) be used (Table 2). Our research team was also very experienced at undertaking fieldwork with 'hard to reach' participants, including vulnerable groups. In most cases, once we had gained peoples' trust, participants talked extensively about their experiences and understanding of OSH in their data-today work, providing us with a rich narrative for analysis.

Data from the structured interviews were coded in two phases, independently by two different researchers, using NVivo 10 qualitative analysis software. This provided a layered approach to coding and reduced the likelihood that themes or issues would be overlooked, since different people - with different backgrounds - will inevitably see different things in data (Morse and Richards, 2002). The first phase involved coding the data deductively against the structured interview protocol, a process that generated 
wide-ranging insights. However, it was clear that other themes and issues had emerged during the interviews that fell outside of the original coding framework. A second researcher therefore coded the structured and semi-structured interview data inductively. Analysis of the ethnographic data relied on the interpretive skills of the ethnographer to reflect on interview transcripts and ethnographic field notes and determine patterns of meaning and action in the words and the activities of participants. The findings from the interviews and ethnographies were reviewed by the different members of the multi-disciplinary research team from the standpoints of their individual specialisms, and were then discussed by the research team in a series of workshops. The workshops generated mutually agreed conclusions about how OSH knowledge is generated, shared, and enacted in smaller organisations. Further details about this approach are discussed in Pink et al (In press)..

\section{Categorising smaller organisations}

There is no universal definition of what constitutes an SME or micro organisation, with categorisations varying from country to country. In the UK, micro, small and medium sized enterprises are classified as organisations employing less than 10, 50 and 250 people respectively, reflecting European Union (EU) guidance (Table 3). Although the EU also uses financial turnover and annual balance sheet to categorise SMEs and micro organisations, employee headcount is undoubtedly the most widely used criterion, perhaps because the financial thresholds are revised over time to reflect changes in the price of goods and services. Such taxonomies are important for government administrators and policy makers, however they are, to a large extent, 
arbitrary and subject to debate and modification ${ }^{3}$. For instance, Forsaith et al. (1995)

argued that staff headcount might not be the most appropriate way to classify

organisations, because enterprises in different industries require different numbers of people for their 'production' processes ${ }^{4}$. In other words, you are not comparing like for like. Developing this line of thinking, Atkins and Lowe (1997) proposed the degree of formalisation - that is to say, the adoption of particular management processes such as budgeting and forecasting - as a better way of differentiating between different 'sized' firms. They argued that this enables firms in different sectors to be compared with each other on 'identical terms'. This approach was supported by O'Regan and Ghobadian (2004), who surveyed 1,000 SMEs in the UK and found “... that while size influences a small number of attributes in leadership, culture and strategic planning, it is not a significant variable.” (p.75).

Table 3: Definitions of medium, small and micro organisations (European Commission, 2003; p.14)

\begin{tabular}{|l|l|l|l|}
\hline $\begin{array}{l}\text { Enterprise } \\
\text { category }\end{array}$ & $\begin{array}{l}\text { Headcount } \\
\text { (annual work unit) }\end{array}$ & Annual turnover & $\begin{array}{l}\text { Annual balance } \\
\text { sheet total }\end{array}$ \\
\hline Medium & $<250$ & $\leq € 50$ million & $\leq € 43$ million \\
\hline Small & $<50$ & $\leq € 10$ million & $\leq € 10$ million \\
\hline Micro & $<10$ & $\leq € 2$ million & $\leq € 2$ million \\
\hline
\end{tabular}

O'Regan and Ghobadian's (2004) findings resonate with the insights from our own research with smaller organisations, which found that the established boundaries between micro, small and medium-sized enterprises were less meaningful in an OSH

\footnotetext{
${ }^{3}$ For example, see Osteryoung and Newman (1993) for an interesting insight into how definitions and classifications of 'a small business' have changed in the United States over time.

${ }^{4}$ Industry structures may also differ. For instance, in construction, many medium-sized contractors would be considered 'large' within the sector because most workers are not 'officially' directly employed, thus unhelpfully underestimating the company size.

${ }^{5}$ The composition of staff headcount is also important, for example, part-time and seasonal workers may be considered in headcount, but those on internships or student placement may not.
} 
context. In our research the prevalence of more formal OSH procedures and processes did typically increase with the size of the enterprise (based on the number of employees), although not necessarily in a linear fashion or in line with the thresholds in Table 3. This was evidenced by what interviewees told us about how their companies approach OSH in the workplace. For instance, the manager of a mediumsized information technology (IT) company explained how, as the business she worked for had grown, OSH had

“...become more of a kind of organised thing, rather than just something that you do when you start and that's been forgotten. I mean we've gotwe have fire marshals on every floor of the building. We've got qualified first aiders who get sent by the company to an outside trainer to get first aid qualifications. So we've got all those kind of areas, that due to the size of the business, we now need to cover.

Figure 2 was developed by the team following a close review of the findings from the data, emphasising that the size of organisation had a noticeable influence on OSH practices at two points in particular. The first, and perhaps biggest change (or articulation point) in OSH practices, was between sole traders and other smaller micro organisations. This difference reflects the fact that the move from sole trader to micro organisation is a significant step, primarily because of the legal obligations of being an employer, but also because of the sense of responsibility that employing people brings with it. For example, one sole trader electrician, who had previous experience of employing people, described how “... as an employer or person, you know who runs a business, you think about that [OSH] a lot more because you think of the consequences of that could happen to somebody else. Somebody working for you and also for the public who are around." Similarly, the owner of a micro organisation in the automotive industry suggested that, if he and his business partner employed 
people, OSH would be “... something we'd be more aware of.”

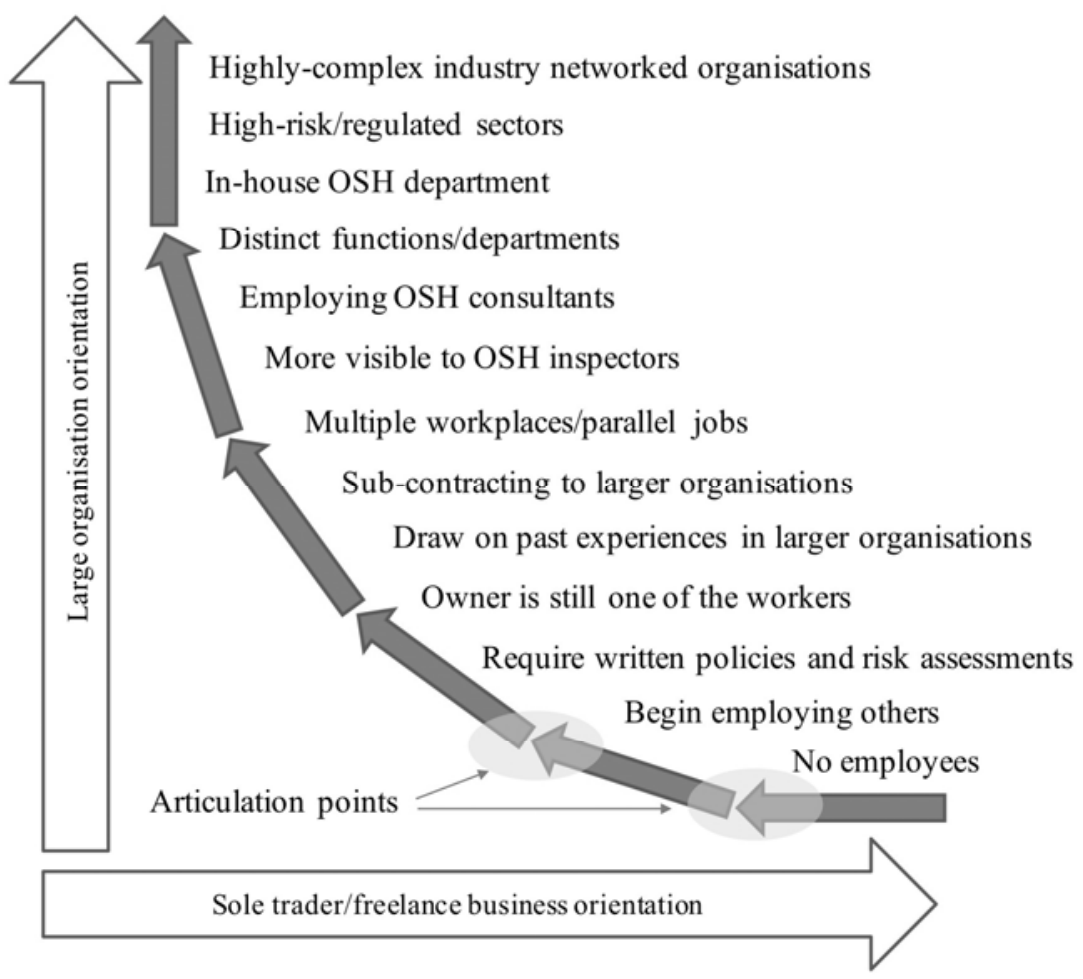

Figure 2: Change in orientation from sole trader to large organisation

The second, albeit less noticeable, change in OSH practices was when organisations employ five or more people. This is an important cut-off point in legal terms because in the UK organisations with fewer than five employees (what might be termed 'nano' enterprises) do not need to have a written OSH policy or to formally record their risk assessments. However, as already mentioned above, the size of organisation was not always the factor that determined the degree of formalisation, nor the risks being considered. Illustrating this point, the owner of a nano healthcare enterprise explained how:

"I took the view that, although a lot of the physios are self-employed, we've got so many people coming to the clinic that it would be remiss not to have a health and safety policy. So we kind of went 'all out' to do all of that in the first place. The physios are very aware that for instance in their 
own work whether they do stuff at home or work in other places, or if they do home visits they're in charge of all their risk assessments and everything like that. But while they're working here they're expected to they sign each year. We have the health and safety logs that they sign each year to say that they will, while they're here, adhere to the health and safety policies here”

OSH practices in the organisations we engaged with appeared to be influenced more by the culture of the organisation, the type of work being undertaken and the sector that an organisation operates in. For instance, even micro companies working within more regulated and/or hazardous sectors, such as mining or healthcare, used more formal OSH processes, whereas similar sized organisations in less hazardous and/or regulated sectors relied much more on informal processes to maintain safe working. Clients and customers were also seen to have an important influence on OSH practices in some sectors. For instance, in the construction industry, larger contractors tended to be more prescriptive about how smaller contractors should work on their sites - subcontractors might be issued with a job description, and have to follow the procedures that their client prescribed. Such influences underline the fact that it would be wrong to view small, medium and micro organisations as homogeneous groups with respect to OSH - health and safety practices are contingent on the context within which they are enacted.

Our research also provided insights into the sometimes blurred relationships that can exist in smaller organisations, which create an additional challenge when researching OSH. For instance, in some sectors, such as agriculture and construction, many workers were talking, acting and treated like 'employees' but were, at least officially, operating as sole traders - a phenomenon usually termed "bogus self-employment" (Briscoe et al, 2000; Harvey, 2001). This blurring of relationships can create a grey 
area when it comes to peoples' legal and ethical responsibilities, and ownership of OSH. Confusion over OSH responsibilities seemed to be more pronounced in situations where sole traders or freelancers were working together on behalf of a client or individually as part of a small or micro business - in other words, where the employer/employee relationship did not exist on paper, but aspects of that relationship remained. One example was a sole trader physiotherapist operating within a small physiotherapy practice - she used the practice's facilities, operated under the practice's brand and was required to adhere to the practice's OSH policies, however she had autonomy over her own OSH practices. Another example of this blurred relationship would be two independent tradespeople working on a domestic construction project, with one 'employing' the other on behalf of the client, the 'employer' abdicating himself of any responsibility for the work or wellbeing of the other individual:

"So if they have an accident or cause any damage, that's on their head, not mine... Which is why it works quite well when you're, like, in my position, for subcontracting work because I have got no responsibility for the other person, financially or any other way" (Sole trader, construction)

In contrast, there were instances in the agricultural sector of self-employed workers acting like employees and being viewed as employees by the owner of the micro company. SMEs and micro organisations therefore create different identities within their relationships, which in turn influences how they approach OSH.

\section{Understanding smaller organisations}

A long-standing criticism of the literature on $\mathrm{OSH}$ is that it has tended to treat smaller organisations as small versions of larger organisations, thereby overlooking their distinctive characteristics and the diverse contexts in which smaller organisations 
operate (Eakin and MacEachen, 1998). Indeed, such criticisms reflect those found in the broader business and management literature, in which authors have argued, variously, that 'children are not little grown ups' (Dandridge, 1979) and that 'a small business is not a little big business' (Welsh and White, 1981). Smaller organisations tend to be characterised as having:

- more informal (and less bureaucratic) cultures, decision-making processes and organisational structures (Ram et al., 2001; Barrett and Rainnie, 2002; Marlow, 2003; Tsai et al., 2007); and

- a greater reliance on (and preference for) tacit learning and knowledge, and informal learning from peers and experience (Gibb, 1997; Deakins, and Freel, 1998).

The characteristics referred to above are seen to be critical to the ability of smaller enterprises to survive, innovate and grow - by being able to quickly respond to opportunities and adapt to change (Jennings and Beaver, 1997) - but they also mean that smaller organisations can be perceived (perhaps unfairly) to be behaving in an ad hoc and reactive manner (Torrès and Julien, 2005). While acknowledging the fact that some larger organisations also share these traits and that smaller enterprises are heterogeneous (O’Regan and Ghobadian, 2004) - SMEs and micro organisations may only exhibit some or indeed none of the above characteristics - it is perhaps unsurprising that such characteristics are reflected in the way that many smaller organisations approach OSH. Our research found that, as explained below, the working practices of many smaller organisations are more compatible with a model 2 view of OSH. This perhaps reflects the fact that smaller organisations often lack the time and resources with which to formally implement, manage and monitor the rules, process and procedures associated with a model 1 approach - they are focused on the 
"realities of production" and the demands of keeping on top of day-to-day business (Barbeau et al., 2004). However, it may also be because management practices in smaller organisations tend to be more informal and less overt, since owners and managers are likely to be working alongside their employees - "I am always here in the shop as well, overseeing things, so I know what my employee is doing”.

Tacit sources of knowledge - common sense, experience and learning by doing were the most frequently cited sources of OSH knowledge amongst our interviewees, having been mentioned by 92 people. Indeed, many of the people we engaged with struggled to articulate how they knew how to work in a healthy and safe manner they "just knew", because it was obvious to them and it was what they did, day in-day out, when working. The importance of tacit knowledge was particularly evident through the role that sensory, embodied, and affective ways of knowing played in ensuring peoples' safety. This suggests that OSH is not only something that is talked about or necessarily easily observed, but is also perceived and enacted in less explicit ways: it is felt and sensed through the bodily, emotional, and sensory experiences of a workplace environment. These ways of knowing were not usually articulated by participants precisely because of their routine and taken-for-granted status. This was particularly the case for people that had experience of doing the same job for many years and for whom working healthily and safely had become "second nature" and "just part of the job". The people that we engaged with explained how they had learnt from their mistakes and near misses, by doing the same task many times, by observing and taking advice from others, and by solving problems encountered during the course of their work. For instance, one employee of a micro engineering firm explained:

“How do I know? A lot of it's common sense. And if you've been using 
machinery and tools and things like that, cutting tools, you basically learn through a lifetime's work"

Previous studies (Antonsson et al., 2002; James et al., 2004) have found that smaller organisations are often reluctant to seek new OSH information. Although that was certainly the case amongst some of our participants, in most cases it was because they felt that their working practices were already safe and that they had the required knowledge and experience to do their work safely. A sole trader in the construction industry explained how:

"Things don't tend to change. New information is generally related to the job in hand or the project I am working on, not really to do with health and safety."

Our findings suggest that SMEs and micro organisations do seek new information when they perceive the need for it, for instance because of a change in legislation, a new type of work or the requirements of a client. For example, the owner of a haulage company described how for certain jobs he can be required to do the same $\mathrm{OSH}$ training that his client provides for its employees; and construction subcontractors working on larger sites are required to receive an induction and familiarise themselves with OSH information provided by the principal contractor. Interestingly, some participants in our study expressed a view that OSH information did not 'flow' to them like other forms of information relevant to their businesses - they had to take the initiative to seek it out, rather than people approaching them with information. The manager of a micro heritage railway felt that it should not be his role to find out about changes in legislation and regulations affecting his business, and that the government department responsible for enforcing the changes should be the ones to tell him. 
Our findings suggest that learning about OSH was more likely to be self-directed in smaller organisations and it was not unusual for people to draw upon multiple sources of information during the course of their work; for instance, a person might use their experience, together with knowledge sourced from their peers and their industry association. Illustrating this point, an employee of a micro agricultural business explained how:

"I learnt from my dad and then you learn on the job. I've also been to college as well, so I have a diploma in agriculture and I've done courses for driving tractor ATVs [All-Terrain Vehicles] and telehandlers”

One particularly interesting insight from our research is the way in which people carry knowledge with them from previous employment(s), which was often (but not always) with larger organisations. In some instances, people carried OSH knowledge with them from a different area of work and then applied it to their new area of business. For example, two people that we interviewed had previously received manual handling training when working for large multi-national companies and now applied that knowledge in their current jobs as market traders. We suggest that this is an important and frequently overlooked source of OSH knowledge in SMEs and micro organisations.

In many respects the literature paints a very negative picture of OSH in SME and micro organisations, with previous studies finding a lack of management commitment (Eakin and MacEachen, 1998; Holmes and Gifford, 1997; Parker et al., 2012), a lack of employee engagement (Champoux and Brun, 2003; Barbeau et al., 2004) and confusion about employee and management responsibilities (Bradshaw et al., 2001; Fairman and Yapp, 2004) in smaller organisations. However, these issues were not really evident in the organisations that we engaged with. On the contrary, the close- 
knit nature of many SMEs and micro organisations meant that owners seemed to feel a sense of responsibility for the health and wellbeing of their employees and similarly employees understood their responsibilities, even if they were not always formalised in writing, because they were seen to be an intrinsic part of their work. The owner of a micro construction firm explained how "I know my job and how to do it - I always want to do things as well as I possibly can and also I want to make sure that we do things safely especially when you are working with family members”. We recognise that it is possible that some interviewees do not know how to work safely even if they think they do. A limitation of our methodology was that our researchers (intentionally) did not make judgements on whether the behaviour described was appropriately safe or not. We acknowledge that there may be quite a difference between what people say when asked and what they actually happens in practice.

Some owners and managers in smaller organisations were keen to stress the importance of their employees being responsible for their own OSH, but this seemed to be less about abdicating responsibility and more about getting employees to buyinto OSH, rather than imposing it on them. The manager of a micro manufacturing enterprise described how:

“... our guys are fully aware of the fact that, if they don't like a process because they don't think it's particularly safe, then we need to find a way of doing the same job in a way that is safe. And this is what we've done. We've looked at things and said, "Well, we don't particularly like that, there must be a better way of doing that." So we found one. And I'm not saying we can't continually improve, because we're always looking to. But at the end of the day, we've come up with what we believe to be the safest and most sensible way of approaching each of the operations that we perform on a regular basis”

It was notable how employees who we engaged did not appear to regard $\mathrm{OSH}$ as 
something 'owned' by their organisation. Their reflections on their working practices suggested that it was less easy for them to separate OSH from their individual responsibility and jurisdiction - OSH becomes 'internal' to practitioners themselves and is expressed through their everyday routines and working practices. OSH practices in SMEs and micro organisations appear to be bound up with a broader notion of 'taking care' of oneself and/or (what could be characterised as) being a 'responsible', 'committed', and 'competent' practitioner (“I wouldn't do anything different than what I'd do for my mother” or “I'm a nurse. You don't take risks”). Interestingly, research with large organisations has found that some OSH managers use the strategy of 'making OSH personal', by illustrating to workers the personal consequences of unsafe behaviour to promote uptake of key safety messages (Gibb et al., 2016b).

Our research highlighted how SMEs and micro organisations develop working practices that, in some cases, might not be in line with formal recognised practice, but that nevertheless appear safe, at least to the worker, within the context that they are being applied. Participants described how they developed - through a process of experiential learning - practices that enabled them to do their work in quicker, easier, simpler, and ultimately (potentially) safer ways. For example, a farmer explained how he had developed safe ways of working with animals in order to ensure that he and his family stayed safe. Such learning was often an integral part of OSH in smaller organisations, informally shared between employees by working with, observing, and talking to each other. This underlines the fact that owners, managers and employees in smaller organisations do not just passively receive OSH information - they use the information to create, shape and adapt knowledge through their everyday practices and interactions with other actors in the workplace. Participants also described how 
safe working, at times, necessarily required that they improvise or adapt their practice to changing features of the workplace and/or work scenarios. This was particularly the case for workers that are 'out in the field' and have less control over their working environment, such as lorry drivers, domestic tradespeople or healthcare workers who visit peoples' homes. For instance, one sole trader in the construction sector described how, when he arrives at a job, the customer will tell him what they want doing and he then "susses out" what needs to be done and carries on and works safely; if he arrived at a place that was unsafe he would choose not work there. In these contexts the ability of (and necessity for) workers to adapt and improvise towards safety is perhaps especially heightened. However, such practices have received little attention in the literature on SMEs and micro organisations and, where they have done, have tended to be viewed as risky and dangerous.

We suggest this is because many researchers have tended to view OSH practices in smaller organisations from a 'model 1' perspective characterised by the use of rigid, top-down rules and standardised procedures. However, such characteristics do not always reflect how many smaller organisations (and some larger organisations) go about their work, meaning that OSH practices that do not conform to this perspective will tend to be looked on negatively, regardless of how safe they are. For instance, the manager of a medium-sized medical practice highlighted the friction that can occur as a result of the difference between what he saw as the medical practice's "lighter touch" approach to OSH and the "tick-box mentality" of people working in the NHS (National Health Service). Being compliant with procedures or legislation does not always mean that something is safe; being non-compliant does not mean that something is not safe. The challenge for OSH researchers and practitioners is therefore to recognise the myriad ways that workers in SMEs and micro organisations 
already work safely. This may mean adopting a pragmatic 'third way' between the model 1 and model 2 perspectives outlined by Dekker (2003) - a continuum along which each situation can be understood as an enmeshed mix of rule-based working and practice-based judgement, as illustrated in Figure 3 . Such as a continuum recognises that there are variations in the proportion of each model due to differences in the individual or group, the task or the environment but that there is always some proportion of both models 1 and 2. This is explored in more detail in Gibb et al. (In Press, p.103-111).

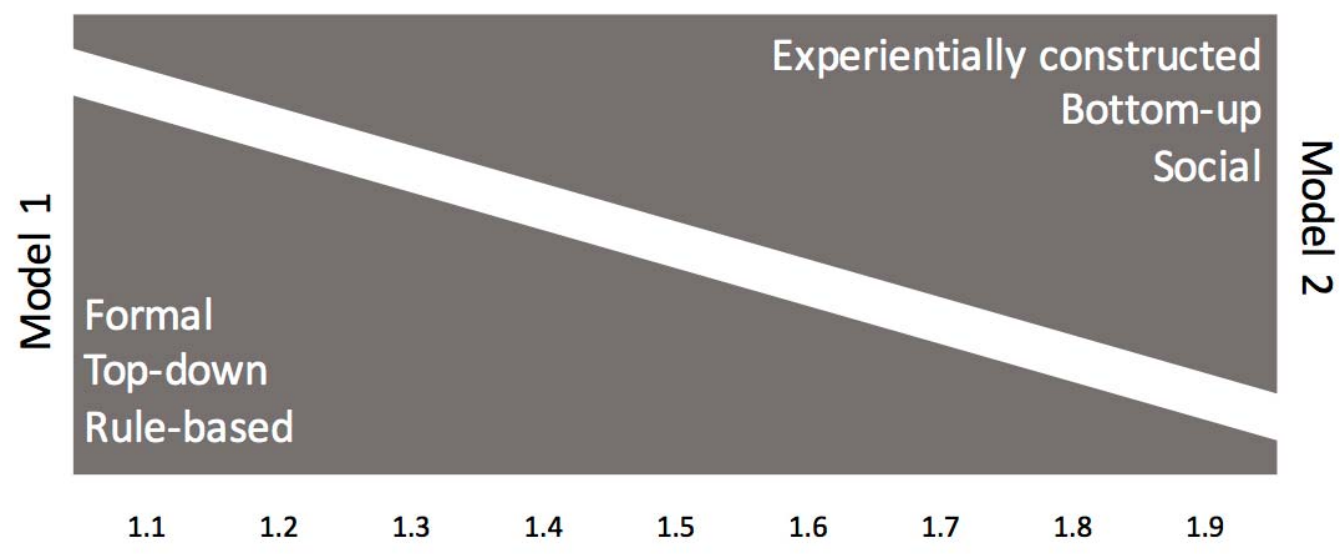

Figure 3: A third-way between model 1 and model 2 perspectives

\section{Conclusions}

A number of conclusions can be drawn from the research discussed in this paper.

First, research within SMEs and micro enterprises is challenging, but useful results can be achieved with tenacious application of an appropriate mixed-methods strategy. Our research suggests that the established boundaries between micro, small and medium-sized enterprises are often less meaningful in an OSH context - OSH practices appeared to be influenced more by the culture of the organisation, the background of individuals involved, the type of work being undertaken and the sector that an organisation operates in, rather than the number of people they employ. 
Although organisations with greater numbers of employees did seem to have adopted more formal OSH policies and procedures, reflecting the findings in the broader business and management literature (Wilkinson, 1999; Knuckey, 2002), the process of OSH formalisation was by no means a smooth progression - it was very 'lumpy' and was further complicated by the varied ways in which SMEs and micro organisations engage with other organisations, both large and small. We found that SMEs and micro organisations create different identities within these relationships, and the shape and nature of these relationships clearly had an influence on the way in which SMEs and micro organisations in our study viewed and approached OSH. There is a tendency to regard micro organisations and SMEs as discrete entities, when in reality they may shift between having organisational characteristics and team characteristics. In other words, the conventional view is too simplistic and should recognise that smaller companies are more complex. Future research could explore in more detail how OSH practices are influenced by different types of relationship and the different identities that SMEs and micro organisations confer on each other and on themselves. Such research might also provide a foundation for a more nuanced investigation into inflexion points in OSH practices that were postulated in this paper, one that moves beyond a focus on employee numbers and puts greater emphasis on the type of work being undertaken, the organisational structure and the culture of the company.

Our research has also revealed how OSH practices in smaller organisations tend to reflect the more informal characteristics of smaller organisations, with a greater emphasis on tacit knowledge, learning by doing and improvisation. For owners and employees in SMEs and micro organisations, these 'other' ways of knowing become part of the everyday enactments that they perform to do their work safely, and the use of 'safe improvisations' is how they adapt to the varied workplace environments that 
they encounter. Whilst acknowledging that there are still those individuals who decide to continue to work in an unsafe or unhealthy manner, we argue that more informal OSH practices should not be assumed to be unsafe or incompatible with formalised OSH. Workers often need to adjust and adapt the 'rules' in order to apply them in a regularly changing environment or task and that a real challenge for OSH practitioners is to develop a culture and practice environment that enables and encourages this level of engagement and does not just condemn such initiative out of hand. Our research has highlighted that there is far more to enacting good, effective OSH than mere compliance - even if the rules were the best and most appropriate rules that could be. It illustrates how workers in small companies skilfully blended diverse ways of knowing, in most cases performing their work in general compliance with OSH regulations yet attuning their practice to the contingencies of varied workplace scenarios and environments. In other words, most 'safety-in-action' is a product of rule following and contingent practice, as illustrated by our 'third way' continuum.

While we do not deny that there is a clear need for formally codified OSH guidance (especially in high-risk work contexts) there is also a need to acknowledge the diverse ecology of safe OSH practices that characterise the workplace, rather than only seeking to understand how OSH could be made better through more comprehensive or tighter regulations. Efforts could then focus on designing applied interventions for helping workers to direct their judgements, responses, and adaptations towards good OSH outcomes. It is essential that OSH researchers and practitioners develop ways of helping SMEs and micro organisations to establish if workers' confidence in working in a safe and healthy manner is actually safe and healthy. Although some studies (Corr Willbourn, 2009; Brace et al., 2009) have looked at this issue in smaller 
organisations in the construction industry, future research could draw on concepts and research techniques developed in the literature on risk perception (e.g. Sjöberg, 2000; Slovic, 2000) and use these to explore how accurately individuals working in SMEs and micro organisations perceive risk: when people think they are using common sense and acting safely, albeit not in accordance with the law, is this actually the case? Where are the areas that people are making the worst misjudgements and how can those be addressed?

\section{Acknowledgements}

The research discussed in this paper was conducted within the 'Engagement of micro, small and medium-sized enterprises in occupational safety and health' project. The project was funded by the Institution of Occupational Safety and Health (IOSH), in their Health and Safety in a Changing World programme. We are grateful to IOSH, and in particular to Robert Dingwall and Jane White, for their support of our work. We also note that part of the text of this paper was included in our report to IOSH (Gibb et al., 2016). The version included in this article has been edited further.

\section{References}

Antonsson, A.B., Birgersdotter, L. and Bornberger-Dankvardt, S. (2002). Small enterprises in Sweden: Health and safety and the significance of intermediaries in preventive health and safety. National Institute for Working Life, Stockholm.

Atkins, M.H. and Lowe, J.F. (1997). Sizing up the small firm: UK and Australian experience. International Small Business Journal, 15(3), pp.42-55.

Atkinson, R. and Flint, J. (2001). Accessing hidden and hard-to-reach populations: Snowball research strategies. Social Research Update, 33(1), pp.1-4. 
Barbeau, E., Roelofs, C., Youngstrom, R., Sorensen, G., Stoddard, A. and LaMontagne, A.D. (2004). Assessment of occupational safety and health programs in small businesses. American journal of industrial medicine, 45(4), pp.371-379.

Barrett, R. and Rainnie, A. (2002). What's so special about small firms? Developing an integrated approach to analysing small firm industrial relations. Work, Employment \& Society, 16(3), pp.415-431.

Brace, C., Gibb, A.G.F., Pendlebury, M.C. \& Bust, P.D. (2009) Health \& Safety in the Construction Industry: Underlying Causes of Fatal Accidents - External Research, Secretary of State for Work \& Pensions - Inquiry into the Underlying Causes of Construction Fatal Accidents

Bradshaw, L.M., Fishwick, D., Curran, A.D. and Eskin, F. (2001). Provision and perception of occupational health in small and medium-sized enterprises in Sheffield, UK. Occupational Medicine, 51(1), pp.39-44.

Briscoe, G., Dainty, A. and Millett, S., 2000. The impact of the tax system on selfemployment in the British construction industry. International Journal of Manpower, 21(8), pp.596-614.

Champoux, D. and Brun, J.P., (2003). Occupational health and safety management in small size enterprises: an overview of the situation and avenues for intervention and research. Safety Science, 41(4), pp.301-318.

Corr Willbourn (2009) Report of qualitative research amongst 'hard to reach' small construction site operators. Health and Safety Executive, Research Report RR719.

Curran, J. and Blackburn, R. (2000). Researching the small enterprise. Sage. 
Dandridge, T.C. (1979). Children are not "little grown-ups": small business needs its own organizational theory. Journal of Small Business Management, 17(2), p.53.

Deakins, D. and Freel, M. (1998). Entrepreneurial learning and the growth process in SMEs. The Learning Organization, 5(3), pp.144-155.

Dekker, S.W. (2014). The bureaucratization of safety. Safety Science, 70, pp.348-357.

Dekker, S.W. (2012). Just culture: Balancing safety and accountability. Ashgate Publishing Ltd.

Dekker, S.W. (2003). Failure to adapt or adaptations that fail: contrasting models on procedures and safety. Applied Ergonomics, 34(3), pp.233-238.

Diefenbach, T., (2009). New public management in public sector organizations: the dark sides of managerialistic 'enlightenment'. Public Administration, 87(4), pp.892-909.

Eakin, J.M. and MacEachen, E. (1998). Health and the Social Relations of Work: A Study of the Health-related Experiences of Employees in Small Workplaces. Sociology of Health \& Illness, 20(6), pp.896-914.

European Commission (2003) The new SME definition User guide \& model declaration. European Commission.

Fairman, R. and Yapp, C., 2004. Compliance with food safety legislation in small and micro-businesses: enforcement as an external motivator. Journal of Environmental Health Research, 3(2), pp.44-52.

Federation of Small Businesses (2016). Statistics. Available from: www.fsb.org.uk/media-centre/small-business-statistics [Accessed 20th February 2016]. 
Forsaith, D., Fuller, D., Pattinson, W., Sutcliffe, P. and Vicente, W. (1995) Defining enterprises by size: Australian empirical evidence on the interchangeability of alternative definitions at the industry level. Flinders University of South Australia, Adelaide.

Gibb, A., Pinder, J., Bust, P. Cheyne, A., Dainty, A., Fray, M., Finneran, A., Glover, J., Hartley, R., Haslam, R., Jones, W., Morgan, J., Pink, S., Waterson, P., Gosling, E. (2016a). Engagement of micro, small and medium-sized enterprises in occupational safety and health. Institution of Occupational Safety and Health, Leicestershire.

Gibb, A., Finneran, A., Cheyne, A., Dainty, A., Glover, J., Morgan, J., Fray,. M, Waterson, P., Bust. P., Haslam, R., Hartley, R., Pink, S. (2016b) Occupational safety and health in networked organisations. Institution of Occupational Safety and Health, Leicestershire.

Gibb, A.A. (1997). Small firms' training and competitiveness. Building upon the small business as a learning organisation. International Small Business Journal, 15(3), pp.13-29.

Hale, A. and Borys, D. (2013). Working to rule, or working safely? Part 1: A state of the art review. Safety Science, 55, pp.207-221.

Harvey, M. (2001). Undermining construction: the corrosive effects of false selfemployment. Institute of Employment Rights, London.

Holmes, N. and Gifford, S.M. (1997). Narratives of risk in occupational health and safety: why the 'good' boss blames his tradesman and the 'good' tradesman blames his tools. Australian and New Zealand Journal of Public Health, 21(1), pp.11-16. 
James, P., Vickers, I., Smallbone, D. and Baldock, R. (2004). The use of external sources of health and safety information and advice: the case of small firms. Policy and Practice in Health and Safety, 2(1), pp.91-104.

Jennings, P. and Beaver, G. (1997). The performance and competitive advantage of small firms: a management perspective. International Small Business Journal, 15(2), pp.63-75.

Knuckey, S., Johnston, H., Campbell-Hunt, C., Carlaw, K., Corbett, L., Massey, C. (2002). Firm foundations: A study of business practices and performance in New Zealand. Ministry of Economic Development, Wellington, New Zealand.

Leonard, D. and Sensiper, S. (1998). The role of tacit knowledge in group innovation. California Management Review, 40(3), pp.112-132.

Lewis, K., Massey, C. and Harris, C. (2007). Learning by doing: six dimensions of complexity in researching SMEs. Qualitative Research in Accounting \& Management, 4(2), pp.151-163.

Marlow, S. (2003). Formality and informality in employment relations: the implications for regulatory compliance by smaller firms. Environment and Planning C: Government and Policy, 21(4), pp.531-547.

Morse, J. and Richards, L. (2002). Read me first for a user's guide to qualitative research. Sage.

O'Regan, N. and Ghobadian, A. (2004). Testing the homogeneity of SMEs: The impact of size on managerial and organisational processes. European Business Review, 16(1), pp.64-77.

Osteryoung, J.S. and Newman, D. (1993). What is a small business? The Journal of Entrepreneurial Finance, 2(3), p.219. 
Parker, D.L., Bejan, A. and Brosseau, L.M., 2012. A qualitative evaluation of owner and worker health and safety beliefs in small auto collision repair shops. American journal of industrial medicine, 55(5), pp.474-482.

Pink, S. and Morgan, J. (2013). Short-term ethnography: Intense routes to knowing. Symbolic Interaction, 36(3), pp.351-361.

Pink, S., Waterson, P., Dainty, A., Cheyne, A., Haslam, A., Gibb, A., Morgan, J., Hartley, R., Finneran, A., and Bust, P. (In press). Interdisciplinary research for occupational safety and health knowledge. Policy and Practice in Health and Safety. Submitted 4/15, accepted 7/16.

Ram, M., Edwards, P., Gilman, M. and Arrowsmith, J. (2001). The dynamics of informality: employment relations in small firms and the effects of regulatory change. Work, Employment \& Society, 15(4), pp.845-861.

Sjöberg, L. (2000). Factors in risk perception. Risk Analysis, 20(1), pp.1-12.

Slovic, P.E. (2000). The perception of risk. Earthscan Publications.

Torrès, O. and Julien, P.A. (2005). Specificity and denaturing of small business. International Small Business Journal, 23(4), pp.355-377.

Tsai, C.J., Sengupta, S. and Edwards, P. (2007). When and why is small beautiful? The experience of work in the small firm. Human Relations, 60(12), pp.17791807.

Welsh, J.A. and White, J.F. (1981). A small business is not a little big business. Harvard Business Review, 59(4), p.18.

Wilkinson, A. (1999). Employment relations in SMEs. Employee Relations, 21(3), pp.206-217. 